\title{
Painting the Past: From Scientific Research to Art
}

\author{
Patricia Vickers-Rich, School of Geosciences, Monash \\ University, Melbourne, Australia, pat.rich@sci.monash.edu.au
}

Understanding the physical and biological conditions that led to the development of complex, multicellular life requires the interaction of researchers with diverse backgrounds. Differences of detail, scale, and terminology between disciplines can confuse. Focused (Eriksson et al., 2004; Valentine, 2004; Schopf and Klein, 1992) and general (see Fedonkin et al., 2007) reviews on Precambrian physical and biological events have helped to bridge gaps between disciplines and have brought about a better understanding of Earth's history. Art can also be a critical "Lingua Franca," allowing cross-disciplinary communication, fueling discussion, and generating new ideas and new approaches to old enigmas.

Major climatic events have become the focus of intense scrutiny, including those at 2400-2200 and 750-560 Ma, when Earth was gripped by cold. The Neoproterozoic cold spell is of special interest to
Figure 1. Bradgatia from the Neoproterozoic of Newfoundland, an early rangeomorph Ediacaran.

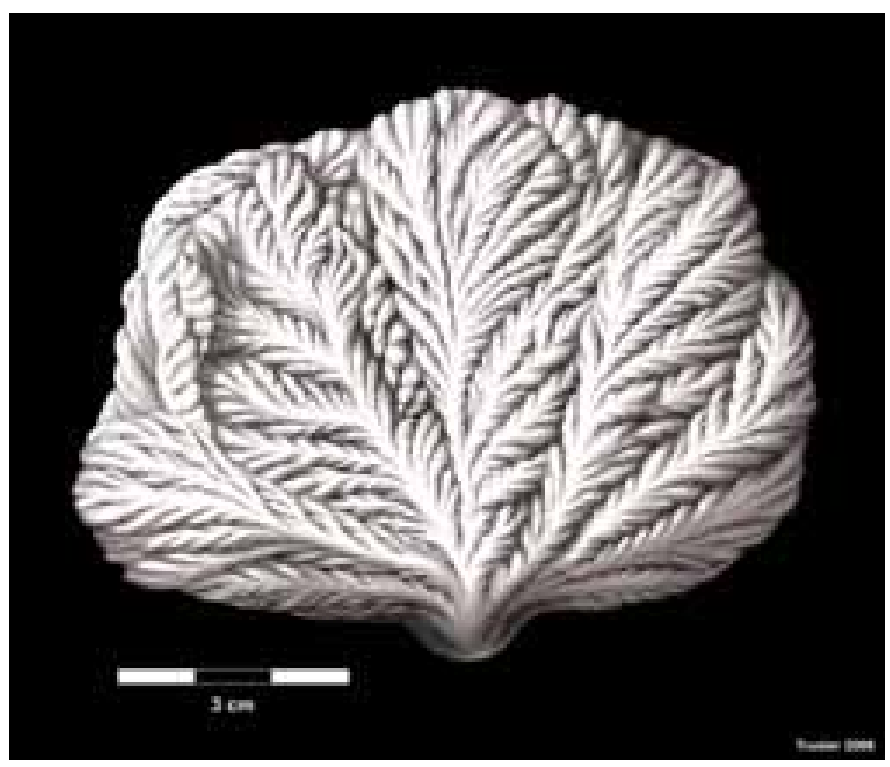
paleontologists attempting to understand the driving forces behind the appearance and diversification of early metazoans. Neoproterozoic climate conditions may have been responsible for the development of dynamic, "weedy," or disturbed environments, which favor evolutionary novelty. Unfortunately, early metazoans (the Ediacarans) lacked hard parts. It is the hard skeletal materials of an organism that most commonly survive post-mortem decay. An additional problem is that the Ediacarans were preserved by environments dominated by microbial mats, making it difficult to develop a detailed understanding of these biota. The Ediacarans contain many taxa with body symmetries unlike those that have come to us via the Phanerozoic, making interpretation a challenge, so much so that the quest for the origin of the major phyla is proving to be problematical. Furthermore, identification of the specific driving forces that led to the origin and radiation of the earliest metazoans and their relationships to the Cambrian explosion of metazoan life are far from being understood.

Here I argue that art can aid in improving our understanding of past life. Peter Trusler is an artist who has worked to render reconstructions of past environments and their inhabitants from the Neoproterozoic to Recent. His art, like that produced by others helping to re-create past life and environments, requires scientists and artist to work together, and provides a summary of our current understanding of the environments populated by now extinct biological entities.

For example, Trusler is developing a series of reconstruction illustrations of the Ediacaran time period. These include the cold depths of the Mistaken Point and Fermeuse biotas of Newfoundland (with Guy Narbonne) ca. 580 $\mathrm{Ma}$ (Fig. 1); the faunal assemblages from the type section of the Ediacaran in Australia (with Jim Gehling; Fig. 2); the White Sea biota of northern Russia (with Mikhail Fedonkin and colleagues); and the latest Neoproterozoic Nama Group of Namibia (with K.H. Hoffmann and colleagues). The strata at these sites were deposited during and after the last of the "Snowball Earth" glaciations (see also www.geosci.monash. edu.au/precsite and www.press.jhu.edu/books/Fedonkin_ Timeline.pdf). These reconstructions of the Ediacaran serve as a focus for discussion and provide the public access to complex scientific ideas.

Our methodology involves Trusler working directly on site, analyzing the excavation environs as well as fossil collections. The final synthesis of geological, taphonomic, and morphological 


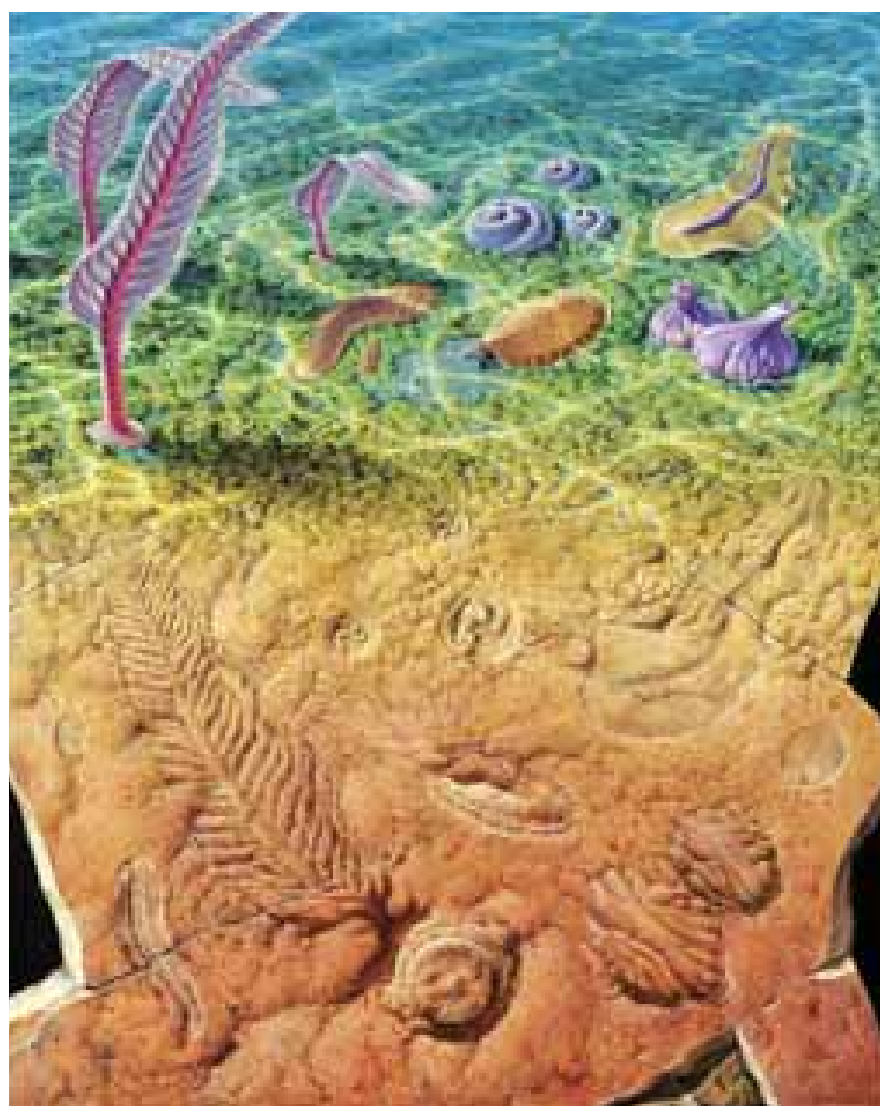

Figure 2. Ediacaran fossils and their reconstruction from the Neoproterozoic of South Australia (courtesy of the Australia Post). This image formed the basis for the stamp issue funded by the Australia Post.

data involves scientists and the artist in transforming them into three-dimensional artistic depictions for scientific scrutiny. Having the artist work directly with researchers has been fundamental. The reconstructions that have resulted encompass paleo-ecological hypotheses and present novel species that can vary significantly from traditional interpretations.

An example illustrates my point. New fossils of tubular organisms, carbonaceous algal remains, abundant Pteridinium, and a new specimen of Rangea have been recovered from Namibia (Fig. 3). Trusler concurred that the new preservation styles of these fossils provided insight into understanding the enigmatic "Rangeomorphs." The fossil assemblage was preserved within a small paleochannel that was full of Rangea, close to the place they had lived. While my colleagues and I carefully mapped where the fossils came from, Trusler sketched rock sequences and fossils.

The data, along with our field notes and photographs as well as sketches of other taxa associated with the Rangea, made up the rest of our observations. Back in the lab, this material was examined along with the sketches and notes taken at other fossil sites around the world. Lengthy discussion with Trusler and my colleagues ensued, and this was complemented by more sketching as well as creation of clay

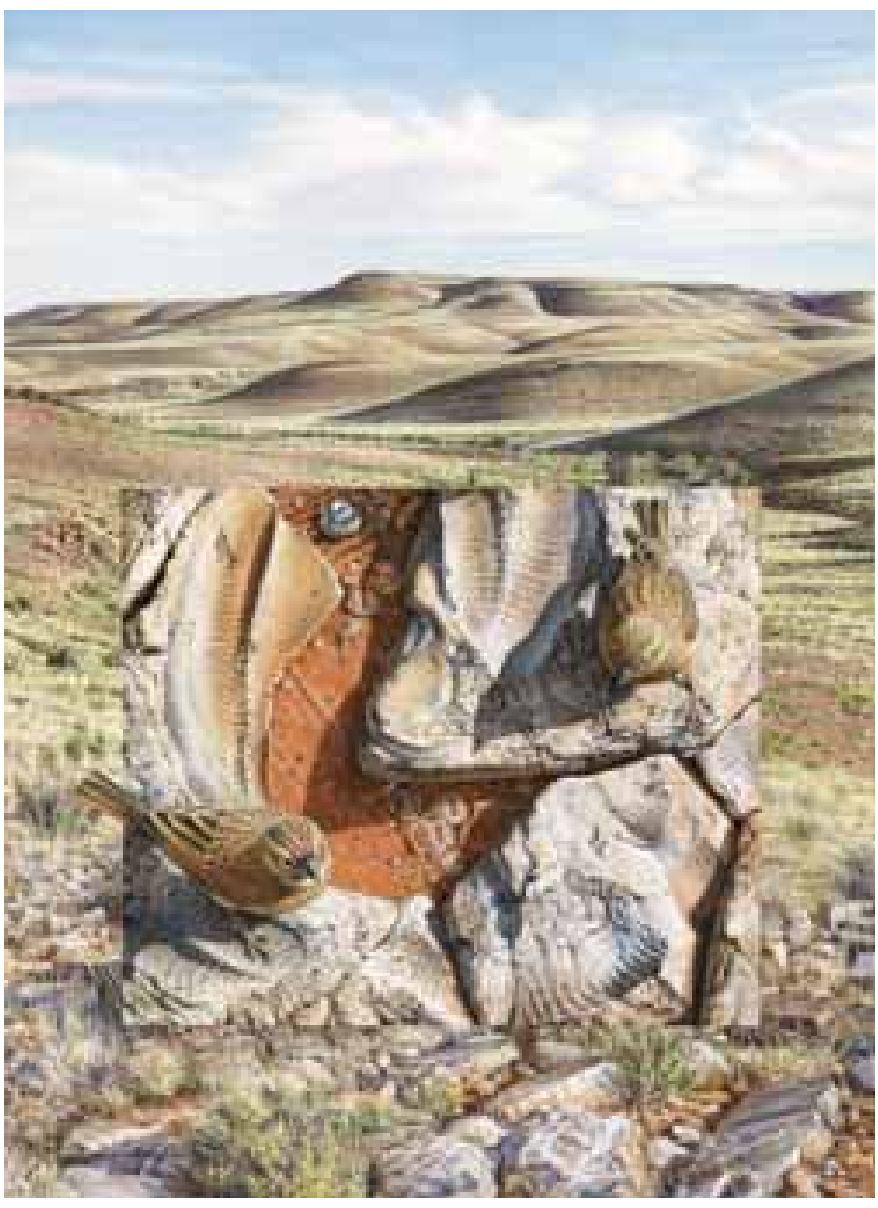

Figure 3. Pteridinium fossils emplaced in the terrain of southern Namibia, where they were discovered in the Neoproterozoic Nama Group.

models. The process was long and meticulous; however, the results, a final set of reconstructions of morphologies and settings, made the effort worthwhile.

The old saying "a picture is worth a thousand words" is not such a cliché; the use of art, and the involvement of an artist, Trusler in our case, has provided insights that words never will.

Manuscript received 29 October 2008; accepted 28 January 2009.

\section{REFERENCES CITED}

Eriksson, P.G., Altermann, W., Nelson, D.R., Mueller, W.U., and Cantuneanu, U., editors, 2004, The Precambrian Earth: Tempos and Events: New York, Elsevier, Developments in Precambrian Geology, v. 12,966 p.

Fedonkin, M.A., Gehling, J.G., Grey, K., Narbonne, G.M., and VickersRich, P., 2007, The Rise of Animals. Evolution and Diversification of the Kingdom Animalia: Baltimore, Johns Hopkins University Press, $327 \mathrm{p}$.

Schopf, J.W., and Klein, C., editors, 1992, The Proterozoic Biosphere-A Multidisciplinary Study: Cambridge, Cambridge University Press, $1383 \mathrm{p}$.

Valentine, J.W., 2004, On the Origin of Phyla: Chicago, University of Chicago Press, 614 p. 